\title{
Advancements in the oral delivery of Docetaxel: challenges, current state-of-the-art and future trends
}

This article was published in the following Dove Press journal: International Journal of Nanomedicine

\author{
Muhammad Farhan Sohail ${ }^{1-3}$ \\ Mubashar Rehman ${ }^{4,5}$ \\ Hafiz Shoaib Sarwar ${ }^{2}$ \\ Sara Naveed' \\ Omer Salman ${ }^{6}$ \\ Nadeem Irfan Bukhari ${ }^{7}$ \\ Irshad Hussain ${ }^{3}$ \\ Thomas J Webster ${ }^{5}$ \\ Gul Shahnaz ${ }^{2}$ \\ 'Riphah Institute of Pharmaceutical \\ Sciences, Riphah International \\ University, Lahore Campus, Lahore, \\ ${ }^{2}$ Department of Pharmacy, Faculty \\ of Biological Sciences, Quaid-i-Azam \\ University, Islamabad, ${ }^{3}$ Department \\ of Chemistry, SBA School of Science \\ and Engineering (SBASSE), Lahore \\ University of Management Sciences \\ (LUMS), Lahore, ${ }^{4}$ Department of \\ Pharmacy, University of Lahore-Gujrat \\ Campus, Gujrat, ${ }^{5}$ Department of \\ Chemical Engineering, Northeastern \\ University, Boston, MA, USA; \\ ${ }^{6}$ Department of Pharmacy, University \\ of Lahore, Lahore Campus, ${ }^{7}$ University \\ College of Pharmacy, University of the \\ Punjab, Allama Iqbal Campus, Lahore, \\ Pakistan
}

Correspondence: Gul Shahnaz Department of Pharmacy, Faculty of Biological Sciences, Quaid-i-Azam University, Islamabad 45320, Pakistan Email gshahnaz@qau.edu.pk

Thomas J Webster

$3 / 3$ Snell Engineering Center, Northeastern University, Boston, MA 02।I5, USA

Email th.webster@neu.edu

\begin{abstract}
The oral delivery of cancer chemotherapeutic drugs is challenging due to low bioavailability, gastrointestinal side effects, first-pass metabolism and P-glycoprotein efflux pumps. Thus, chemotherapeutic drugs, including Docetaxel, are administered via an intravenous route, which poses many disadvantages of its own. Recent advances in pharmaceutical research have focused on designing new and efficient drug delivery systems for site-specific targeting, thus leading to improved bioavailability and pharmacokinetics. A decent number of studies have been reported for the safe and effective oral delivery of Docetaxel. These nanocarriers, including liposomes, polymeric nanoparticles, metallic nanoparticles, hybrid nanoparticles, dendrimers and so on, have shown promising results in research papers and clinical trials. The present article comprehensively reviews the research efforts made so far in designing various advancements in the oral delivery of Docetaxel. Different strategies to improve oral bioavailability, prevent firstpass metabolism and inhibition of efflux pumping leading to improved pharmacokinetics and anticancer activity are discussed. The final portion of this review article presents key issues such as safety of nanomaterials, regulatory approval and future trends in nanomedicine research.
\end{abstract}

Keywords: anticancer, permeability enhancement, solubility enhancement, P-glycoproteins, efflux pump, first-pass metabolism

\section{Introduction}

Cancer incidence is increasing globally and accounts for about 8.2 million deaths worldwide mainly because of poor tumor targeting and severe dose-related adverse effects to other organs or many other complications associated with the disease. ${ }^{1}$ Cancer incidence is higher in developing countries that bear $57 \%$ of all cases and $65 \%$ of all deaths because of a steady increase in population growth rate, repeated exposure to carcinogens, poor hygiene and many other factors. ${ }^{2,3}$ This dramatic increase in the number of cancer patients would need inexpensive and convenient therapies to alleviate their suffering and improve their quality of life. ${ }^{4}$ Current cancer treatment involves intrusive processes starting initially with chemotherapy to reduce the tumor size, followed by surgical procedures to remove the solid tumor and, if required, another course of chemotherapy and radiation for the complete eradication of cancer cells. ${ }^{5,6}$ Most current anticancer agents are administered intravenously (IV), which requires proper supervision by a trained person during the course of therapy and makes the treatment very expensive. ${ }^{7,8}$

Oral drug delivery is the most convenient way to administer medicine. ${ }^{9}$ But oral administration of cancer chemotherapeutic drugs is limited due to an extensive 
first-pass effect, ${ }^{10}$ poor solubility, ${ }^{11}$ efflux transport, ${ }^{12}$ low intrinsic permeability of drug limits, bioavailability of drugs and so on. ${ }^{13}$ Despite the aforementioned limitations, the oral delivery of chemotherapeutic drugs is highly desirable in terms of its convenience in synthesis and administration, ease of design, vast variety of formulations and, most importantly, better patient compliance in terms of chronic ailments. ${ }^{14-16}$ The oral route can be used for systemic as well as localized gastrointestinal tract effects. For systemic applications, the oral route is preferred because of the highly absorptive nature of the intestine that provides a large surface of around 300-400 $\mathrm{m}^{2}$ for drug adsorption and varying physiological conditions which also facilitate different types of outcomes not associated with other routes of chemotherapeutic administration. ${ }^{17,18}$ The oral administration of chemotherapeutics may be of great importance in the following clinical cases: $:^{1,19}$

1. Maintenance of plasma drug concentration necessary to produce inhibitory effects on cancer cells.

2. Drug release could be controlled in a better way compared to other routes.

3. Enables chronic treatment, especially with cell cyclespecific agents, such as signal transduction inhibitors, which may result in improved pharmacodynamics compared to intravascular administration.

4. Improved patient compliance as it avoids needles related to discomfort, hazards and special care.

5. Pharmacoeconomics is another prime consideration for many patients, which could be addressed by using oral delivery.

The majority of available anticancer drugs, including "taxanes" (Paclitaxel and Docetaxel [DTX]), belong to the biopharmaceutical classification system class IV, and their clinical use is limited due to their extreme hydrophobicity, low water solubility, low bioavailability and high toxicity. ${ }^{20,21}$ In the past two decades, many types of cancers have been efficiently treated by taxanes, that is, DTX and Paclitaxel, as they can disrupt microtubule function and cause cell apoptosis and death. ${ }^{22}$

The delivery of hydrophobic drugs has always been a challenge and it is still a hot research topic since they cannot reach the intracellular environment by crossing the cell membrane because of the surrounding aqueous environment in tissues and organs, whether given orally or IV..$^{23,24}$ Molecular drug discovery and development are expensive and intense processes taking over a decade and over US $\$ 5$ billion on average. ${ }^{25}$ In contrast, designing new drug delivery systems for existing drug molecules with established efficacy is a much more beneficial research area in terms of both time- and cost-effectiveness. Pharmacological properties of a drug can be greatly improved by selecting an appropriate carrier system based upon the route of administration. ${ }^{26}$

Taxanes share the largest sales volume of around US $\$ 3.5$ billion of the presently available anticancer drugs. ${ }^{27}$ Thus, development of an oral formulation for DTX would be a great achievement from the patient's perspective of "chemotherapy at home" ${ }^{28,29}$ The present review is designed to highlight the various challenges encountered in the oral administration of DTX and nanomedicine-based strategies to address these challenges.

\section{Challenges in the oral delivery of DTX}

DTX is a semisynthetic taxane (Figure 1A) prepared by the chemical modification of an inactive precursor obtained from the needles of the European yew tree (Taxus baccata) ${ }^{30}$ It acts by disrupting the microtubule network that blocks cell cycles in the late $\mathrm{G} 2$ and $\mathrm{M}$ phases, thus inhibiting cell replication as shown in Figure 1B. ${ }^{31}$ DTX has been proven to be better in efficacy as compared to Paclitaxel. ${ }^{32}$ The drug has a clinically significant antitumor activity against a range of tumor types and is approved for the treatment of breast cancer, ${ }^{33}$ ovarian cancer, ${ }^{34}$ non-small cell lung cancer (NSCLC), ${ }^{35}$ head and neck carcinoma, ${ }^{36}$ gastric cancer ${ }^{37}$ and prostate cancer ${ }^{38}$ at doses ranging from 60 to $100 \mathrm{mg} / \mathrm{m}^{2}$ administered at 1 hour infusions every 3 weeks. ${ }^{39}$ Weekly IV schedules of DTX result in similar efficacy and a different toxicity profile with a lower incidence of febrile neutropenia compared to three-weekly schedules. Management of neutropenic infections requires patient hospitalization and treatment with IV antibiotics. The other major side effect is neuropathy that is related to cumulative doses and can potentially limit the number of cycles that can be given. ${ }^{40}$

Bioavailability of the drug after oral administration is the key determinant of any delivery system in order to achieve therapeutic outcomes. ${ }^{41}$ Dissolution in acidic gastric fluid and permeation across the enterocytes are the rate-limiting factors that govern oral bioavailability. Generally, these rate-limiting factors can be divided into two main categories: 1) physicochemical properties of the drug molecule (ie, solubility, $\log P$, dissolution and stability) and 2) physiological factors associated with the gastrointestinal tract (ie, $\mathrm{pH}$, gastric retention time, absorption window, enzymatic degradation, hepatic first-pass effect and P-gp efflux pumps). ${ }^{42,43}$

\section{Physicochemical properties of DTX}

The most important physicochemical properties of the drug are its aqueous solubility and membrane permeability, which 

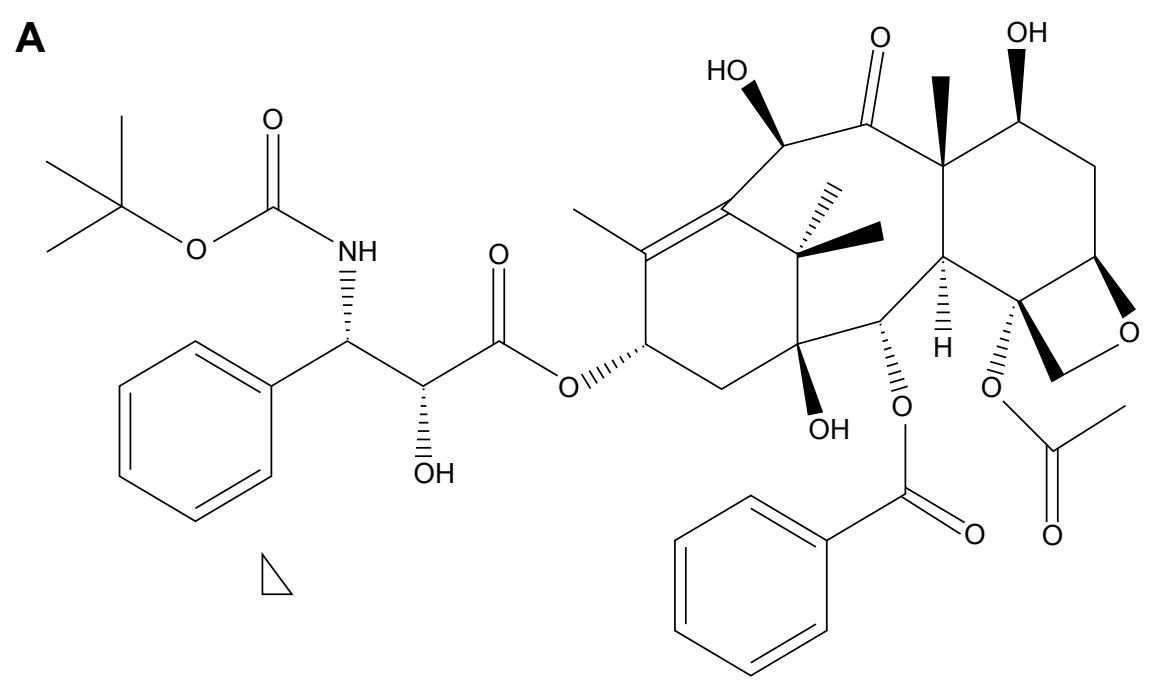

B

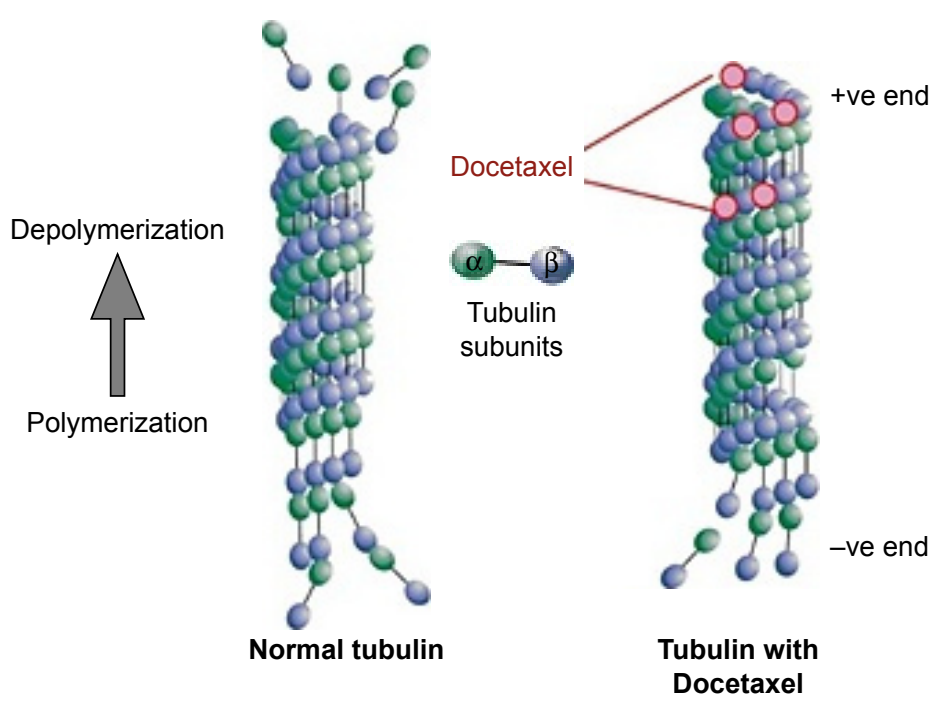

Figure I (A) Chemical structure of Docetaxel and (B) graphical representation of the mechanism of action of Docetaxel.

are explained in the Lipinski's rule considering the Pka and $\log P$-values of the drug. ${ }^{44}$ DTX has a Pka=10.97 and $\log$ $P=4.1$, which results in poor aqueous solubility $(0.025 \mu \mathrm{g} / \mathrm{mL})$ and low membrane permeability $\left(1 \mathrm{~cm} / \mathrm{s} \times 10^{-6}\right) .{ }^{1,45}$ The pharmacodynamics of a drug is fully dependent on its pharmacokinetics (ie, absorption, distribution, metabolism and excretion profile). ${ }^{46}$ The absorption of a drug could be calculated by Fick's law of diffusion, and drugs have been categorized as dissolution rate limited, permeation rate limited and both dissolution/permeability limited accordingly. ${ }^{47,48}$ Poor dissolution and higher $\log P$-value place DTX in a dissolution/permeability limited category. Similarly, the biopharmaceutical classification system categorizes it as a class IV drug having both low solubility and permeability. ${ }^{49,50}$

\section{Physiological barriers for DTX}

The molecular bases of physiological barriers faced by many anticancer drugs after oral administration are still unknown and are constantly being investigated. However, two of the most important barriers faced by anticancer drugs, including DTX, are hepatic first-pass clearance by the cytochrome P450 (CYP450) enzyme system and the P-gp efflux pump, which are further explained in the section "Pre-systemic metabolism" and "Transmembrane efflux of drugs". ${ }^{51}$

\section{Pre-systemic metabolism}

Oral bioavailability is the collective fraction of a drug available systemically after 1) absorption from the gastric mucosa and 2) absorption from the enterohepatic circulation, and 3) the fraction available after the first-pass effect. The gastrointestinal absorption of the drug is affected by a number of factors (ie, metabolism by different metabolic enzymes [amylase, peptidase, lipase and so on], normal flora of the intestine, brush border metabolism [peptidase, alkaline phosphatase, sucrose and so on] and intracellular metabolism carried out by an extrahepatic microsomal enzyme in the 
endoplasmic reticulum). ${ }^{52}$ Cytochrome P2A4 (CYP3A4) includes phase II enzymes such as esterases, glutathiones, transferases and so on that are present in enterocytes and act at the gastrointestinal wall, which could also serve as a target for the amide or ester prodrugs. The hepatic first-pass effect by the CYP450 family is the other major contributor for decreasing oral bioavailability. ${ }^{53}$ DTX is an extensively protein-bound drug, as $>98 \%$ of it systemically is bound to alpha- 1 acidic glycoproteins and albumin. ${ }^{54}$

\section{Transmembrane efflux of drugs}

Clinically significant cellular transport systems (such as P-gp, cytoplasmic transport, multidrug-resistant associated protein and fluorochrome efflux) can decrease the oral bioavailability of many drugs which are the substrate of these transporters via an efflux mechanism..$^{55}$

P-gp, a membrane-associated protein belonging to ATP binding cassette transporters, is extensively distributed throughout the intestinal epithelia, hepatocytes, kidneys and capillary endothelial cells forming blood-brain and bloodtestis barriers. These P-gps are mainly involved in developing multidrug resistance against many anticancer drugs. P-gp activity is induced by two ways - either by endogenous lipids and peptides or by drugs which are the substrate for it. Depending on the vulnerability, anticancer agents could be divided into three categories. Class I drugs can stimulate P-gp in low concentrations and inhibit it at higher concentrations. On the other hand, class II drugs can cause dose-dependent activation of ATPase leading to lower bioavailability of the substrate drugs and class III drugs can inhibit the activity of ATPase, increasing drug bioavailability. ${ }^{56} \mathrm{DTX}$ is a substrate of P-gp and belongs to class II, contributing to its decreased oral bioavailability. ${ }^{57}$ Currently, the development of drug resistance is regarded as a major obstacle to the success of cancer chemotherapy. Due to the presence of drug efflux transporters, pharmacological responses from non-penetrative routes of chemotherapy is at the most moderate. ${ }^{58}$

\section{Current status of the DTX formulation}

Taxotere $^{\circledR}$ (Sanofi-Aventis, Anthony Cedex, France) is US Food and Drug Administration (FDA)-approved, IV-administered DTX formulation commercially available. It contains a combination of DTX and Tween 80, a nonionic surfactant from the polyethylene glycol class, to overcome the prime issue of poor aqueous solubility. It was approved for NSCLCs in December 1999, prostate cancer in May 2004, breast cancer in August 2004, gastric cancer in March 2006 and for head and neck cancers in October 2006. ${ }^{59}$

During clinical trials, DTX was supplied as a sterile solution containing Tween 80 and ethanol (50:50), but the commercially available formulation contains a reduced amount of Tween 80 ( $26 \mathrm{mg} / \mathrm{mg}$ of DTX), which is further diluted with $13 \%$ ethanol before injection into the patients. Due to the presence of Tween 80 , many cases of mild to severe hypersensitivity were reported along with peripheral edema, weight gain and pericardial effusion with a dose above $400 \mathrm{mg} / \mathrm{m}^{2}{ }^{20-62}$

Tween 80, especially its metabolic product, and oleic acid result in histamine-induced hypersensitivity associated with DTX formulations, ${ }^{63}$ although pathogen-induced vasoactive substance release is also labeled as a possible mechanism. The association with peripheral edema may be supported by the fact that the vehicle has increased membrane permeability. Lastly, Tween 80 has shown changes in plasma viscosity and red blood cell morphology, which induce cardiovascular side effects of DTX therapy ${ }^{64}$ Recent studies have also shown the antiangiogenic ability of both DTX and Tween 80 at low concentrations, but the clinically achieved concentration after DTX infusion abolishes the antiangiogenic potential. ${ }^{62}$ Tween 80 also greatly influences the pharmacokinetics of DTX by increasing the concentration of unbound DTX in the plasma, due to formation of Tween 80 micelles, that interacts with alpha acidic proteins. ${ }^{65}$ Also, the higher plasma level of Tween 80 decreases the plasma clearance of DTX, resulting in severe hematology toxicity due to the unbound drug. ${ }^{62}$ All these problems strongly demand for the development of Tween 80-free formulations for DTX with improved pharmacokinetics and pharmacodynamics of the drug.

\section{Emerging trends in oral delivery of DTX}

Despite the fact that most of the anticancer drugs, including DTX, face challenges after oral administration in achieving optimum bioavailability to produce the desired effects, promising and encouraging results after oral administration have been reported by various scientists. Also, developing Tween 80 -free formulations with improved pharmacokinetics, pharmacodynamics and better tumor targeting has led to several new possibilities. ${ }^{1}$ Various strategies have been reported with successful increases in dissolution and permeation of DTX after oral administration. A comprehensive review of all these techniques is described in next section. 


\section{Coadministration of other agents - beneficial effect of drug interactions}

Coadministration of DTX with a molecule showing inhibitory effects on major barriers of oral administration could also improve its oral bioavailability. For example, coadministration of cyclosporine A with DTX has shown a successful increase in oral bioavailability. Oral administration in rat and dog models has shown a $14 \%-17 \%$ increased peak plasma concentration and a 17 -fold decreased clearance, thus showing that cyclosporine A can alter the disposition of orally administered DTX ${ }^{66}$ A clinical study was conducted on cancer patients by administering $15 \mathrm{mg} / \mathrm{kg}$ cyclosporine 30 min preceding the oral administration of DTX. The results showed $8 \%$ absolute bioavailability without cyclosporine, which significantly increased to $90 \%$ with cyclosporine. ${ }^{67}$ A similar effect was shown by piperlongumine on the oral bioavailability of DTX by inhibiting CYTP3A4 metabolism and P-gp and by improved cytotoxicity when coadministered. This strategy successfully improved the oral bioavailability 1.68-fold in rats via permeation enhancement and decreased efflux pump activity 0.64 -fold. ${ }^{68}$ The inhibition of CYP3A4 and P-gp, major contributors in limiting oral bioavailability of DTX, can significantly improve the oral bioavailability. A research study conducted on mice lacking all genes for CYP3A4 and P-gp showed significant improvement in oral bioavailability. However, this resulted in intestinal lesions with lethal toxicity, highlighting the potential application and serious concerns of this option, especially with drugs having a narrow therapeutic index. ${ }^{69}$ Coadministration of DTX with a cell penetrating peptide has also shown potential in increasing the oral bioavailability of DTX as well. In one study, cyclodextrin-poly(lactic-co-glycolic acid) (PLGA) nanoparticles (NPs) loaded with DTX and an R7 cell penetrating peptide showed increased toxicity against MCF-7 cells and a 9.47-fold increased oral bioavailability. ${ }^{70}$ Therefore, coadministration of DTX with an inhibitor may be a suitable platform to enhance its oral bioavailability.

\section{Nanocarrier-based approaches}

The advent of nanotechnology has created much hype and introduced many possibilities in every field. In medicine, it has introduced so many possibilities in therapeutics and diagnostics that it could be named as the future of efficient personalized drug delivery. ${ }^{71,72}$ After decades of multidimensional research in nanotechnology, it has already started to show a great potential for improving drug delivery systems as evident from the increasing number of nanomedicines gaining FDA and European Medicines Agency approval. ${ }^{73}$ These engineered nanocarriers can be tuned for their sizes ranging from 1 to $1,000 \mathrm{~nm}$, surface properties such as charge and ligands attached for specific cellular receptors, and shape based upon the features required for carrying a specific molecule to a target site to achieve a desired therapeutic outcome. ${ }^{74}$ NP-based drug delivery systems have significantly improved cancer therapy and reshaped the landscape of the pharmaceutical industry. ${ }^{27}$

Nanotechnology-based delivery systems are potential solutions for the oral administration of highly efficient chemotherapeutic drugs such as DTX. ${ }^{75}$ These nanocarriers can be prepared with different materials such as polymers, lipids, inorganic materials, metals and proteins or the hybrids of these materials to tune the nanocarriers (Figure 2) for specific purposes. ${ }^{76}$

The nanoscale drug delivery vehicles (eg, liposomes, prodrugs, core-shell polymeric NPs, metallic NPs, solid lipid NPs and so on) have been explored with several advantages noted, which are as follows:

1. Improved bioavailability by overcoming the solubility or permeability of the molecules.

2. Protection of the drug molecule from harsh environments (eg, against enzymatic degradation by lysozymes, proteases in systemic circulation or highly acidic $\mathrm{pH}$ of the stomach).

3. Better tumor targeting through surfaces decorated with ligands for specific receptors or using a $\mathrm{pH}$-sensitive polymer releasing drug in a specific environment inside the tumor.

4. Control of drug release patterns to achieve site-specific release and to maintain the required plasma drug concentration.

5. Co-delivery of drug combinations or along with diagnostic agents for magnetic resonance imaging, computed tomography or positron emission tomography to achieve better therapeutic outcomes and improve patient compliance. ${ }^{77}$

Drug-drug interaction in patients receiving oral chemotherapy has been reported, which is a major concern in developing more personalized and target-specific carriers for the oral administration of chemotherapeutics. ${ }^{78}$ Generally, nanocarriers having particle sizes around $300 \mathrm{~nm}$, positive zeta potential and hydrophobic surfaces have preferential uptake from the enterocytes. ${ }^{79}$ Many research groups have explored these properties for the oral administration of DTX. Different mechanisms of increased oral bioavailability of 


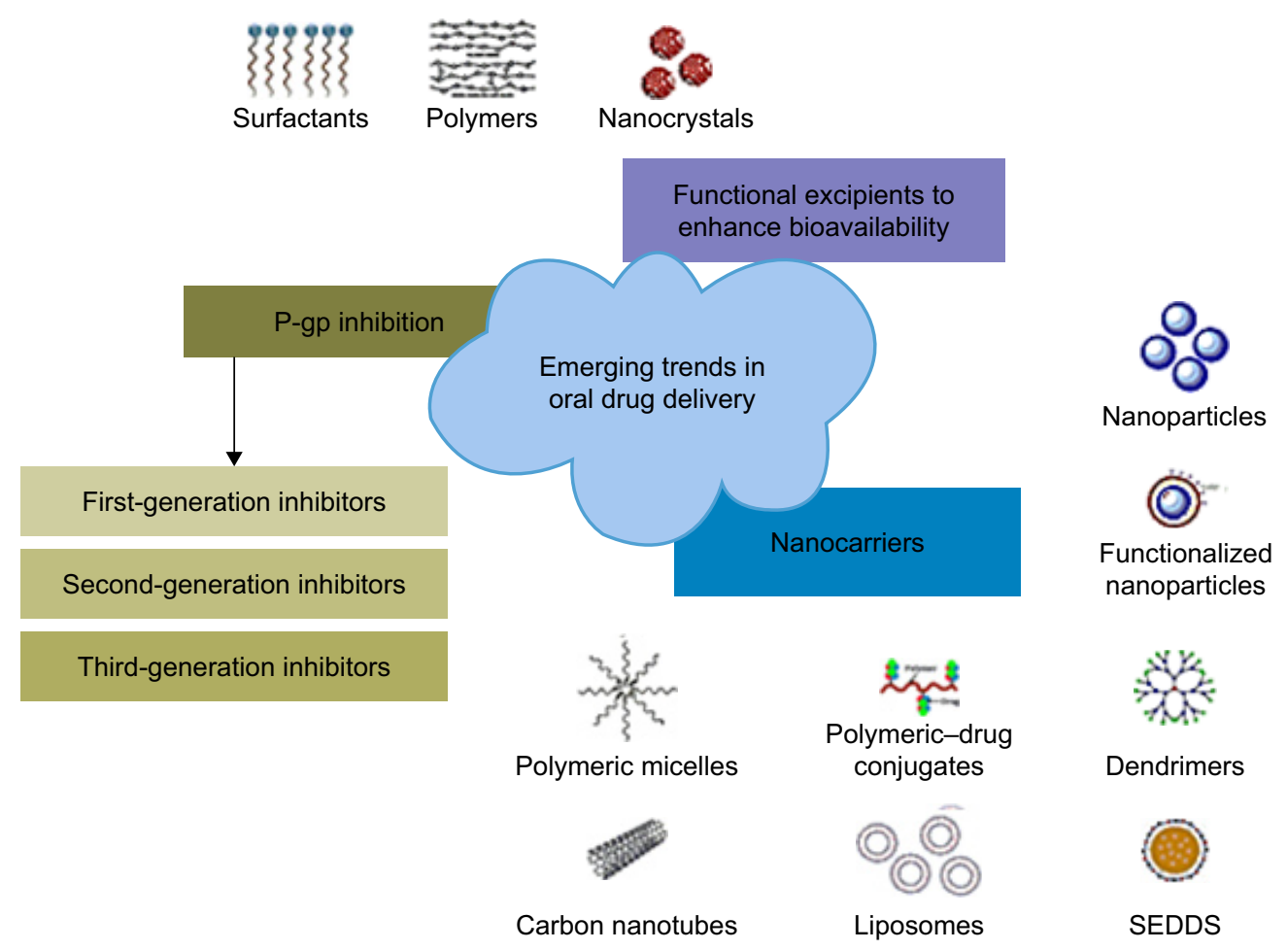

Figure 2 Nanotechnology based emerging trends reported for the oral delivery of anticancer agents. Abbreviation: SEDDS, self-emulsifying drug delivery systems.

DTX release have been explored through nanocarriers, including facilitating a paracellular route by modulating tight junctions (through interactions with tight junction proteins), mucoadhesion (either due to electrostatic interactions between the positive surface charges of NP and the negatively charged mucin or a covalent linkage developed between the functional groups at the NP surface and cysteine of mucin), phagocytosis by specialized Peyer's patches (M-cells or mucosa-associated lymphoid tissue), receptor-mediated transcytosis or endocytosis and lymphatic absorption via chylomicron uptake mechanisms from the enterocytes. In addition to this, persorption has been proposed, wherein a carrier-loaded or lepidic formulation permeates through temporary gaps at the cell apex, generated as a result of the migration of the continuously produced intestinal cells in the crypts of Lieberkuhn toward the tip of the villus during digestion. ${ }^{80}$ These mechanisms are shown in Figure 3.

\section{Polymeric NPs}

Polymeric nanocarriers have extensively been explored for the oral delivery of anticancer drugs with improved safety profiles. The major advantages of using polymers for drug delivery are their biocompatibility, biodegradability, versatility in linking to different molecules to develop co-block polymers and, most importantly, attachment of functional/targeting moieties to them. Polymers for oral administration include PLGA, chitosan, gelatin, dextran, alginate and acrylic acid derivatives. The capability to achieve sustained release from the polymeric nanocarriers up to several days is of great interest as it helps to overcome the tissue barriers until it reaches systemic circulation. Similarly, several reports have shown rapid uptake of nanocarriers by the M-cells of immune system or via the lymphatic system, enabling their systemic availability and prolonged release profile.

DTX-loaded polycaprolactone/Pluronic F68 NPs with particle sizes around $200 \mathrm{~nm}$ and drug loading up to $69 \%$ have been developed with significantly improved cytotoxic potential against MCF-7 breast cancer cells, as compared to IV DTX and Tween 80. The presence of Pluronic F68 not only increased the cytotoxicity of NPs toward cancer cells, but also influenced drug release from the NPs, making it more controlled ${ }^{81}$ PLGA is the most widely used FDAapproved material and is found in different applications in nanomedicine. NPs loaded with DTX were also synthesized with vitamin E-PLGA-succinate derivative, also known as docetaxel-loaded d- $\alpha$-tocopheryl polyethylene glycol 1000 succinate (TPGS), and montmorillonite for oral delivery. A sustained release of up to 3 weeks after a single oral administration and 21-fold increased bioavailability were achieved as compared to IV DTX and Tween 80. Due to solubilizing and 


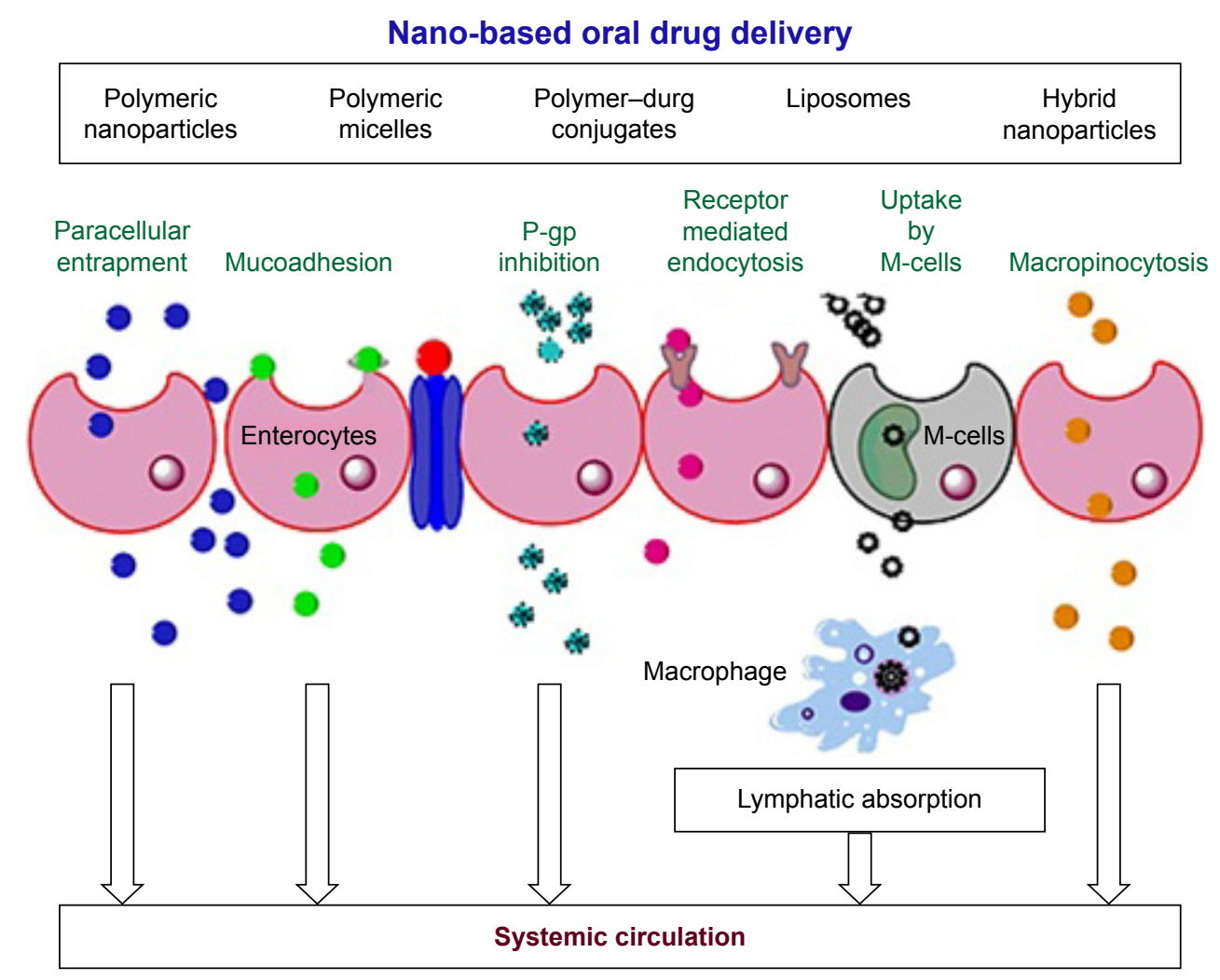

Figure 3 Different cellular mechanisms involved in the cellular uptake and permeation of various nanoformulations across the enterocytes after oral administration.

P-gp inhibiting properties of TPGS, $\mathrm{IC}_{50}$ value of DTX was improved four times and the half-life after oral administration was increased 26 times as compared to IV DTX and Tween $80 .{ }^{82}$ Another way to improve oral bioavailability is to enhance gastric retention of the NPs. Accordingly, DTX-loaded nanocarriers were prepared by using polymethyl methacrylate coated with thiolated chitosan, which is a mucoadhesive and enhances permeability from the gastrointestinal tract after oral administration. The in vivo pharmacokinetics revealed a 9-fold increase in half-life and 96\% increased oral bioavailability as compared to DTX. ${ }^{83}$ Lecithin has also been reported to successfully increase the oral bioavailability of DTX due to its solubility and permeation enhancing effects. In vitro studies showed a sustained drug release and improved permeation on a Caco-2 cell line. The oral bioavailability had a 3.65-fold increase in permeation as compared to a DTX suspension in rats. ${ }^{84}$ Mucoadhesive polymeric NPs were also prepared by using methyl- $\beta$-cyclodextrin and poly (isobutylcyanoacrylate) with an outer shell of thiolated chitosan. The synthesized NPs showed a good enhancement for permeation during in vitro studies ${ }^{85}$ Sulfobutylether- $\beta$-cyclodextran and chitosan-based NPs were developed for the coadministration of DTX and berbamine. The newly formed NPs showed good drug loading and release kinetics and improved cytotoxicity against MCF-7 cells. The oral bioavailability of the DTX was relatively improved with significantly improved cytotoxicity. The cytotoxicity of NPs is another major concern which needs to be addressed when designing a carrier. NPs composed of methyl- $\beta$-cyclodextrin/polyisobutylcyanoacrylate coated with thiolated chitosan have shown decreased enterocyte toxicity and inflammation followed by oral administration of DTXloaded NPs as compared to IV DTX and Tween $80 .{ }^{86,87}$

Chitosan-loaded DTX NPs surface modified with PLGA were reported for improved oral bioavailability and tumor uptake. ${ }^{88}$ In this study, the apparent permeability across the rat intestine showed a 5 -fold increase in the presence of a third-generation P-gp inhibitor and a 2.2-fold increase without it. Oral pharmacokinetics showed a 5.11-fold increased oral bioavailability as compared to a DTX suspension. The presence of a P-gp inhibitor in formulations improved cellular uptake (A549 cells) as well, confirming the role of P-gp inhibition and nanocarriers in the successful oral delivery of DTX. A similar core-shell system comprising thiolated chitosan shell and polymethyl methacrylate core is reported for the improvement in oral delivery of DTX. Particles with $>200 \mathrm{~nm}$ size showed $90 \%$ entrapment efficiency. The system controlled DTX release for 10 days with an initial burst release. The carrier efficiently transported DTX across 
the rat intestine and showed improved toxicity against $\mathrm{Caco}-2$ and MCF-7 cell lines. ${ }^{89}$

\section{Lipid-based nanocarriers}

Lipid-based materials have also proven their importance as a drug carrier, including solid lipid NPs (SLNs), liposomes, micro-/nanoemulsions, ethosomes, lipid-based tablets, proliposomes, lipopolymeric hybrid nanocarriers and so on. ${ }^{90}$ Of these, liposomes are the only successful carrier approved by the FDA and a number of products are now available in the market. ${ }^{91}$ The first anticancer liposomal doxorubicin was approved by the FDA in 1995. Since then, many more liposomal drugs have been evaluated and are in different phases of clinical trials. ${ }^{92}$ The most important feature of liposomes is their ability to incorporate both hydrophilic and hydrophobic moieties and deliver them to the site of action through the extravascular as well as intravascular routes of administration. Liposomes are thermodynamically stable vesicles with an aqueous core surrounded by an amphiphilic phospholipid bilayer. ${ }^{93,94}$ On the other hand, SLNs and nanostructured lipid carriers (NLC) have shown advantages such as higher drug loading, higher permeability and prolonged storage stability, as compared to other lipid-based nanocarriers for the delivery of anticancer drugs. A couple of groups have investigated lipid-based nanocarriers for increasing the oral bioavailability of DTX with promising results. For example, aoleic acid-linked DTX prodrug in liquid form was formulated as NLC by mixing with a solid phase lipid that increased the prodrug loading up to 5-fold. These NLC also showed a 4-fold increased bioavailability and significantly improved oral permeability as compared to a DTX solution. ${ }^{95}$

Cysteine-modified lipid nanocarriers for the oral delivery of DTX have been reported with good in vitro permeation enhancement and pharmacokinetic parameters. The permeation enhancement was facilitated by both passive transport and absorption in enterocytes via improved mucoadhesion of the surface cysteine. Oral pharmacokinetics revealed a 13-fold increase in the area under the curve as compared to a DTX suspension. ${ }^{96}$ Another carrier comprising Tween 80 and TGPS 1000 as emulsifiers showed increased oral bioavailability of the DTX-loaded SLN as compared to IV DTX and Tween 80. Bioavailability was further increased with TGPS containing SLNs, possibly due to blockage of P-gp and absorption through the lymphatic system. ${ }^{97}$

\section{Hybrid NPs}

Hybrid nanocarriers, composed of two different materials, have been introduced for the delivery of many therapeutic agents with improved therapeutic outcomes as compared to individual components. The hybrid NPs mostly consist of polymer-lipids, polymer-metal or lipid-polymer hybrid materials. ${ }^{98}$ Hybrid nanocarriers have shown some good results in the oral delivery of cancer therapeutics, including the successful delivery of DTX.

A core-shell system consisting of a polymeric core and lipid shells was functionalized with folic acid for the oral delivery of DTX. The main advantage of the formulation was controlled drug release (about 60\%) after 72 hours and a $94 \%$ better cytotoxicity against MCF-7 when compared to IV DTX and Tween $80 .{ }^{99}$ A similar hybrid nanocarrier system has been developed by our group for the successful oral delivery of DTX. The nanocarriers consisting of folic acid-labeled polymeric-enveloped nanoliposomes showed high stability and improved in vitro and in vivo properties. The in vitro permeation showed a 9.6-fold increased permeation in the rat intestine and a 13.6-fold increased oral bioavailability as compared to a DTX suspension. Tumor targeting and cytotoxicity were greatly improved against MDA-MB-231 cells, possibly because of P-gp inhibition by thiolated chitosan and better tumor targeting with surface folic acid. ${ }^{100}$

Another interesting carrier based on a carboxymethyl chitosan phospholipid bilayer capped mesoporous carbon NP was reported for the oral delivery of DTX with sustained release. ${ }^{101}$ This hybrid nanocarrier was successful in maintaining a high pay load due to an anionic lipid layer and later showed pH-responsive sustained release in gastric media owing to a cationic polymer envelopment. Moreover, the nanocarriers showed improved mucoadhesion. Improved oral bioavailability of DTX was also reported using DTX-loaded nanocapsules prepared from glyceryl tributyrate, oleoyl polyoxylglycerides and PLGA 4000 embedded in Eudragit L and HPMC microparticles. The formulation increased oral bioavailability and $\mathrm{C}_{\max }$ in minipigs by 10 - and 8.4-fold, respectively. The NCs successfully transported DTX across the enterocytes with a reduced biodistribution and plasma release and improved anticancer activity in metastatic lung cancer, compared with IV DTX and Tween $80 .{ }^{102}$

\section{Theranostic nanocarriers}

Theranostic nanocarriers are gaining importance in cancer therapeutics as they have the ability to carry a drug molecule along with some diagnostic agent that helps to track disease treatment, perhaps in real time. A couple of theranostic nanocarriers with DTX have been reported in the literature with good results. Theranostic liposomes coated with vitamin $\mathrm{E}$ derivatives (TPGS) were designed for the 
delivery of DTX along with quantum dots for diagnosis. These targeted liposomes showed better cellular uptake and a 41-fold lower $\mathrm{IC}_{50}$ against MCF-7 cells, as compared to IV DTX and Tween $80 .{ }^{103}$ Another study reported a hybrid nanosystem with a PLGA core encapsulating superparamagnetic iron oxide NP and DTX within a folate-chitosan shell for magnetic resonance imaging and improved delivery of DTX. The in vitro study against folate-positive and -negative cancer cells showed improved uptake by a folate-positive cell line with no effect on magnetic properties and an overall shortened $\mathrm{T}_{2}$ relaxation time. ${ }^{104}$

\section{Emulsions}

Emulsion-based formulations are the most common way of efficiently administering lipophilic drugs. To overcome problems such as thermodynamic and kinetic instability, two new types of emulsions have been synthesized, that is, microemulsion and nanoemulsion. Many research groups have reported improved oral bioavailability of DTX by using emulsion-based formulations.

\section{Microemulsion}

The solubility of DTX has been improved to a $30 \mathrm{mg} / \mathrm{mL}$ concentration using the microemulsion technique. The formulation was successfully synthesized with $30 \mathrm{~nm}$ particle sizes and remained stable for 24 hours upon a 20 -fold dilution. In vitro studies showed a very good release profile and permeation enhancement of the formulation as compared to IV DTX and Tween 80. This improvement was further confirmed by a $34.4 \%$ increase in oral bioavailability in rats after oral administration owing to P-gp inhibition and increased permeation. ${ }^{105}$

\section{Nanoemulsions}

Nanoemulsions comprising soybean oil and lecithin were prepared with Pluronic F68 and PEG 4000 as an emulsification system for the oral delivery of DTX. The formulation successfully delivered DTX to MCF-7 breast cancer cells with a 2.8-fold enhanced uptake as well as higher anticancer activity in mice without any toxic effects on the liver and kidney. ${ }^{106}$ Another article reports the successful oral delivery and P-gp inhibition by a nanoemulsion of a naturally occurring frankincense oil. The resultant formulation was stable and showed improved uptake and P-gp inhibition in a Caco-2 cell line and low $\mathrm{IC}_{50}$ against MDA-MB-231 cells. A significantly higher oral bioavailability of 180 -fold resulted in a $19 \%$ more antiproliferative effect than IV DTX and Tween 80 , suggesting a high potential for formulation development. ${ }^{107}$

\section{Self-emulsifying drug delivery systems (SEDDS)}

SEDDS form the next generation to emulsions, which rely on the interaction with physiological fluids for the synthesis of micro- or nanoemulsions. The system consists of drugs dissolved in oils and stabilized by surfactants which, upon reconstitution with an aqueous environment and gentle agitation, turn to emulsion as a function of SEDDS composition.

A self-nanoemulsifying drug delivery system (SNEDDS) was prepared by using Capryol 90, Labrasol and Transcutol HP and exhibited 17\% increased oral bioavailability, improved antitumor activity and reduced nonspecific toxicity as compared to IV DTX and Tween $80 .{ }^{108}$ In another study, spray-dried solid SNEDDS containing colloidal silica were synthesized as an oral carrier for DTX. These SNEDDS produced a nanoemulsion in water and showed $12.5 \%$ absolute bioavailability as compared to a clear DTX solution given either via IV or orally. ${ }^{109}$ Another approach used to enhance the oral bioavailability of DTX used a solid supersaturable emulsifying drug delivery system. The system showed improved oral bioavailability of DTX in rats, as revealed by an 8.77 - and 1.45 -fold increased area under the curve as compared to DTX and conventional SEDDS. ${ }^{110}$ In another study, curcumin-based SEDDS were orally administered with DTX in rats, which showed improved bioavailability 2.4- to 3.2-fold on increasing curcumin concentration. No effect on the clearance of DTX was observed with curcumin, which suggested the inhibition of CYP450 (3A) and P-gp in the intestine. ${ }^{11}$ SEDDS with DTX were synthesized using Capryol 90, vitamin E, Gelucire 44/14 and Transcutol HP with the aim to increase oral bioavailability, block chylomicron flow and improve biodistribution. Oral bioavailability in rats increased by 3.19-fold and cytotoxicity increased by 25 -fold as compared to the IV DTX solution. ${ }^{12}$

\section{Polymer-drug conjugate}

Drug-polymer conjugates provide another possibility of delivering drugs with certain advantages over encapsulation in the polymeric NPs. In this strategy, a drug is conjugated to a polymer by biodegradable chemical bonds to control drug loading and release kinetics. Many natural and synthetic polymers have been explored for conjugation with the drug, leading to cost-effective, biocompatible and biodegradable formulations. By careful selection of the polymer, increased dissolution and permeation have been achieved with improved pharmacokinetics and pharmacodynamics.

Polysaccharides such as dextran, hyaluronic acid, carboxymethylcellulose and chitosan have all shown very good results when conjugated with different drugs of the taxane 
family. DTX covalently attached to low-molecular-weight chitosan has shown good antitumor activity in vivo. ${ }^{113}$ Pharmacokinetic studies were conducted in mice bearing nonsmall cell lung carcinoma and a 15 -fold increase in half-life was achieved as compared to IV administration of DTX. Moreover, the conjugate also produced low toxicity in terms of weight loss and hematological analysis. In another study, DTX was covalently attached to taurocholic acid linked to heparin, which resulted in self-assembled NPs. The results showed a 6-fold higher oral bioavailability, probably because of bile acid transporter in the small intestine. The formulation also resulted in better cytotoxicity and tumor accumulation of NPs as compared to controls, against MDA-MB-231 and KB tumor models. ${ }^{114}$ Carboxymethyl chitosan-linked DTX was suggested for improved oral bioavailability and tumortargeting potential. The formulation indicated improved in vitro properties, and in in vivo conditions, mice bearing B16 melanoma showed improved bioavailability and tumor uptake as compared to DTX solution and a 4-fold decrease in toxicity. ${ }^{115}$

\section{Micelles}

Polymeric micelles are nanostructures composed of an inner hydrophobic core and a hydrophilic corona facing the aqueous environment. The hydrophobic core acts as a drug reservoir and the corona as a steric stabilizer ensuring stability of the system. Polymeric micelle-based nanocarriers have gained much importance recently because of their high solubilizing capacity, improved blood circulation time, small size and targeting ability. ${ }^{116}$ Their importance and various mechanisms of oral absorption such as membrane permeation, receptor-mediated pinocytosis, inhibition of efflux transporters and mucoadhesion make them a potential candidate for the oral delivery of anticancer drugs. ${ }^{1,117}$ Oral delivery of DTX has been reported using different polymeric micelles with some good results.

Polymeric micelles composed of polycaprolactone and polyethylene glycol have been used to increase oral permeation of DTX. The micelle system is further entrapped in a $\mathrm{pH}$-responsive hydrogel for release into the intestinal lumen and subsequent absorption from the small intestine. The in vivo studies showed a 10 -fold increased oral bioavailability with the hydrogel-based system as compared to the micelles alone. Better tumor suppression against a 4T1 breast cancer model, along with decreased systemic toxicity was observed as compared to standard IV therapy. ${ }^{118}$ In another study, micelles formed of beta-casein have been reported for the oral delivery of DTX for gastric cancer.
The nanosized micelles showed good stability and improved physicochemical properties of DTX, leading to increased oral bioavailability. ${ }^{119}$ DTX was also successfully delivered by co-block polymeric micelles composed of monomethylol poly(ethylene glycol)-poly (D,L-lactic acid), D- $\alpha$-tocopheryl polyethylene glycol 100 succinate and a stearic acidgrafted chitosan oligosaccharide. The formulation showed good in vitro characteristics and a 2.52-fold increased oral bioavailability as compared to a DTX suspension. ${ }^{120}$ Oral bioavailability of DTX has been successfully improved by micelles composed of stearic acid-modified Bletilla striata (an orchid species native to China, Japan, Korea and so on). The formulation showed good biocompatibility and cytotoxicity against different cancer cells including HepG2, Hela and MCF-7. The results indicated a 2- to 4-fold increased toxicity as compared to IV DTX. ${ }^{121}$

A nano-in-micro vector-based carrier was investigated for the improved oral bioavailability of DTX. ${ }^{122}$ In this study, biotin-modified micelles containing DTX were encapsulated in alginate microparticles targeting the intestinal permeation and a sodium-dependent multivitamin transporter for improved oral bioavailability. The formulation was characterized for various parameters and proved its stability for drug loading and release. A significantly improved oral bioavailability of 24.7-fold as compared to DTX and an $84.6 \%$ improved anticancer activity against sarcoma 180 was achieved with this dual targeting vector. DTX-loaded micelles in $\mathrm{pH}$-responsive hydrogels were also reported to increase oral pharmacokinetics. The in vitro characterization of the formulation showed controlled release in the intestinal media due to $\mathrm{pH}$ responsiveness and improved cytotoxicity against a 4T1 breast cancer model. Oral administration showed a 10 -fold increased bioavailability with enhanced antitumor effects, indicating a very good oral delivery potential of the formulation. ${ }^{118}$ A nanomicelle formulation was also reported for the improved solubility and oral bioavailability of DTX. Micelles comprising Tween 20 and 80 resulted in $14 \mathrm{~nm}$ micelles with a $99 \%$ encapsulation of DTX. The formulation showed prolonged release in gastric fluid with a decreased $\mathrm{IC}_{50}$ compared with IV DTX and Tween 80 . The formulation dramatically improved the solubility of DTX around 1,500 times, that is, $10 \mathrm{mg} / \mathrm{mL}$ in micelles as compared to $6 \mu \mathrm{g} / \mathrm{mL}$ in water. ${ }^{123}$ Another group reported methoxy poly(ethylene glycol)-poly(lactide) micelles with different size ranges to study the effect of the size of administration and distribution. The results indicated an $84.4 \%$ improved oral epidermoid tumor inhibition and cell penetration of DTX-loaded pH-responsive micelles. ${ }^{124}$ 


\section{Proniosomes}

Niosomes are lamellar structures composed of nonionic surfactants with additives to improve their characteristics. Due to the disadvantages associated with their lamellar structures, the dry powder forms of niosomes, termed as proniosomes, have been prepared, which show niosomal dispersion upon rehydration in aqueous solution. Proniosomes are relatively stable and cheaper with improved features as compared to liposomes and other nanocarriers. ${ }^{125}$ Proniosomes are studied for their transdermal delivery, oral delivery, buccal delivery and IV delivery of various classes of drugs. TPGS-modified proniosomes have also been studied for the oral delivery of DTX with improved antitumor activity. The developed formulation was stable in terms of particle size and potential with homogenous synthesis. ${ }^{126}$ Later, an in vitro study showed improved permeation across a Caco-2 cell monolayer. Oral pharmacokinetics showed a 7.3-fold improved absolute oral bioavailability compared to a DTX solution and significantly higher antitumor efficacy in MCF-7-bearing mouse model. ${ }^{127}$

\section{Solid dispersion}

Solid dispersions of DTX have been prepared to overcome the limitations of low aqueous solubility. In in vitro studies, Soluplus solid dispersion showed up to 93-fold increase in DTX solubility. ${ }^{50}$ A poloxamer F-68/F-85-based solid dispersion has been reported to improve the oral bioavailability of DTX. The formulation is based on a mixture of Poloxamer F68 and Poloxamer F85, and showed a 2.97-fold improved bioavailability as compared to Poloxamer F68 alone, thus showing that F85 has a better potential as a permeation enhancement excipient in the formulation. ${ }^{124}$ Another attempt to improve pharmacokinetics by using solid dispersion was made by using DTX with PVP-K-30 and sodium lauryl sulfate. The capsule-filled solid dispersion was tested in a Phase I clinical trial using ritonavir as a pharmacokinetic booster and was compared to IV DTX and Tween 80 . The results showed no significant difference in pharmacokinetics, except for higher and more variable exposure to DTX after oral administration of Taxotere, which showed a major advantage with low intraindividual variability and the absence of ethanol and polysorbate in the formulation. ${ }^{49}$

\section{Toxicity concerns}

Local toxicity associated with modified drug delivery systems, especially with nanocarriers, is a serious concern in the oral delivery of anticancer agents (DTX). The whole production cycle of the nanomedicine is different from conventional pharmaceuticals in terms of production, distribution, clinical administration and waste disposal. Therefore, there is a prime need of intensive in vitro and in vivo toxicity profiling of oral administration. Despite all the advancements in the recent past, scientists are still struggling to clearly describe the toxicokinetic of these nanomedicine formulations and little research efforts have been put in this area to date. ${ }^{128}$ The in vitro cytotoxicity screening of the polymers and other biomaterials cannot predict cytotoxicity, hemocompatibility and biocompatibility of such nanomedicines. ${ }^{129}$ In addition to this, toxic effects may be encountered due to large surface area, high absorption capacity, the aggregation state and surface coating of the NPs. ${ }^{130}$ Therefore, nanotoxicological evaluations of these new carriers should involve collaborations of scientists from cellular biology, molecular biology, pharmacology, chemical engineering, biotechnology and toxicology. Recently, Giardiello et al have reported accelerated oral nanomedicine discovery of human immunodeficiency virus drugs from miniaturized screening to clinical production. This process facilitated the synthesis and optimization of a miniaturized library of nanomedicines that are screened for physicochemical properties, in vitro and in vivo pharmacological evaluation and pilot-scale production of batches for clinical applications. This strategy is also applicable for multiple drug-loaded nanomedicines. ${ }^{131}$

\section{Regulatory aspects}

According to the above discussion, nanomedicine-based approaches have shown promising results in the oral delivery of DTX as summarized in Table 1. Although different regulatory agencies, such as the FDA, have established programs for accelerated approval of oncology products, the toxicity data of newly developed drug delivery systems are insufficient and may hinder the regulatory affairs for their approval and commercialization. ${ }^{132}$ Therefore, an early dialogue between the regulatory agencies and manufacturing will ensure successful exploration of health, safety and environmental aspects of the nanomedicine development process. In addition, a diverse library of reagents, experiments and equipment are available for the same purpose. This has created difficulty in interpretation and comparison of results reported by different authors. Therefore, uniformity in experiments is needed and standardized protocols must be developed for reproducible and, hence, more trustable science. ${ }^{133}$ Nevertheless, new technologies including instruments, methods and techniques must be designed to meet the ever-increasing and unmet needs of nanomedicine safety assessment. Multidisciplinary studies including material 
Table I Different nano-based approaches used for the oral delivery of Docetaxel

Serial Material Characterization Outcomes
no.

no.

Polymeric nanoparticles

I. Polycaprolactone/Pluronic F-68

2. PLGA, vitamin E, montmorillonite

3. Polymethyl methacrylate, thiolated chitosan In vivo

4. Lecithin In vitro

5. Methyl- $\beta$-cyclodextrin and thiolated chitosan In vivo

6. Sulfobutylether- $\beta$-cyclodextrin and chitosan In vivo

7. Methyl- $\beta$-cyclodextrin, polyisobutyl In vitro cyanoacrylate, thiolated chitosan

8. Chitosan, PLGA

9. Glyceryl tributyrate, oleoyl polyoxylglycerides In vivo and in vitro and PLGA 4000 NC embeded in Eudragit L and HPMC microparticles

\section{Lipid-based nanocarriers}

I0. Oleic acid-Docetaxel prodrug

II. Cysteine-modified lipid nanocarriers with PEG 2000

12. DTGPS 1000, Tween 80

\section{Hybrid nanocarriers}

I3. Polymeric core-lipid shell

14. Mixed lipid core and folate grafter thiolated chitosan shell

I5. Carboxymethyl chitosan, phospholipids, mesoporous carbon NPs

Theranostic nanocarriers

I6. Liposomes, TPGS with quantum dots In vitro

I7. SPION, PLGA, folate-chitosan In vitro

\section{Emulsions}

18. Microemulsion Caproyl 90, Cremophor EL, Transcutol

19. Nanoemulsion soybean oil, lecithin, Pluronic F68, PEG 4000

20. Frankincense oil-based nanoemulsion

Self-emulsifying drug delivery systems

21. SNEDDS Capryol 90, labrasol, Transcutol HP In vivo

22. SNEDDS based on colloidal silica In vivo

In vivo and in vitro

In vivo and in vitro

In vitro
Increased cytotoxicity and controlled drug release as compared to IV Docetaxel and Tween 80

Improved oral pharmacokinetics with a 21 -fold

increased oral bioavailability and sustained release over 3 weeks as compared to IV Docetaxel and Tween 80 .

Also, a 3- to 4-fold increased anticancer activity was observed

A 9-fold increased half-life and $96 \%$ increased oral bioavailability via increased permeation

The oral bioavailability was increased 3.65 -fold as compared to a Docetaxel suspension

Improved oral bioavailability with a sustained release effect

A I,447\% increased oral bioavailability and decreased plasma clearance

Decreased enterocyte toxicity and inflammation as compared to IV Docetaxel and Tween 80

A 5-fold increased permeation and 5.II-fold increased anticancer activity against A549

A 10 - and 8.4-fold improved oral bioavailability and $C_{\max }$ compared with IV Docetaxel and Tween 80 . Increased antitumor effect against metastatic lung cancer

A 4.04-fold increased oral bioavailability as compared to Docetaxel

In vivo and in vitro A I3-fold increased AUC as compared to Docetaxel

Increased oral bioavailability as compared to

IV Docetaxel and Tween 80 via P-gp blocking and lymphatic uptake

Sustained release and $94 \%$ better cytotoxicity as compared to IV Docetaxel and Tween 80

In vivo and in vitro A 9.6-fold increased permeation and 13.6-fold increased oral bioavailability as compared to Docetaxel suspension Improved mucoadhesion, sustained drug release in gastric $\mathrm{pH}$ and improved anticancer activity

Improved cellular uptake with a $4 \mathrm{I}$-fold increased cytotoxicity as compared to IV Docetaxel and Tween 80 Improved cellular uptake and shortened $\mathrm{T}_{2}$ relaxation time for better imaging

In vivo and in vitro A $34.3 \%$ increased oral bioavailability as compared to IV Docetaxel and Tween 80 . Sustained release over 12 hours

2.8-fold increase in cellular uptake and least toxic effect against a MCF-7 cell line

In vivo and in vitro $\quad$ 182.5-fold increased relative oral bioavailability and $19 \%$ increased anticancer activity against MDA-MB-23I

$17 \%$ increased oral bioavailability and antitumor activity as compared to IV Docetaxel and Tween 80

$12.5 \%$ increased oral bioavailability as compared to a Docetaxel solution 
Table I (Continued)

\begin{tabular}{|c|c|c|c|c|}
\hline $\begin{array}{l}\text { Serial } \\
\text { no. }\end{array}$ & Material & Characterization & Outcomes & References \\
\hline 23. & $\begin{array}{l}\text { Supersaturable self-emulsifying drug delivery } \\
\text { system }\end{array}$ & In vivo and in vitro & $\begin{array}{l}\text { Improved oral bioavailability by } 8.77 \text {-fold and AUC by } \\
\text { I.45-fold as compared to IV Docetaxel and Tween } 80\end{array}$ & 110 \\
\hline 24. & SEDDS curcumin & In vivo & $\begin{array}{l}\text { 2.6- to } 4.4 \text {-fold increased } C_{\max } \text { and } 2.4 \text { - to } 3.2 \text {-fold } \\
\text { improved oral bioavailability }\end{array}$ & 111 \\
\hline 25. & $\begin{array}{l}\text { SEDDS Caproyl 90, vitamin E, Gelucire } \\
44 / 14 \text { and Transcutol HP }\end{array}$ & In vitro and in vivo & $\begin{array}{l}\text { A } 3.19 \text {-fold increased oral bioavailability and a } 25 \text {-fold } \\
\text { increased cytotoxicity }\end{array}$ & 112 \\
\hline \multicolumn{5}{|c|}{ Polymer-drug conjugates } \\
\hline 26. & Chitosan-Docetaxel & In vivo and in vitro & $\begin{array}{l}\text { I5-fold increased half-life as compared to a Docetaxel } \\
\text { solution and decreased toxicity }\end{array}$ & 113 \\
\hline 27. & Taurocholic acid-heparin-Docetaxel & In vivo and in vitro & $\begin{array}{l}\text { 6-fold increased oral bioavailability with improved tumor } \\
\text { targeting and uptake in MDA-MB-23I cells }\end{array}$ & 114 \\
\hline 28. & Carboxymethyl chitosan-Docetaxel & In vivo and in vitro & $\begin{array}{l}\text { Improved oral bioavailability and tumor targeting with a } \\
\text { 4-fold decreased toxicity }\end{array}$ & 115 \\
\hline \multicolumn{5}{|c|}{ Polymeric micelles } \\
\hline 29. & Polycaprolactone, PEG & In vivo and in vitro & $\begin{array}{l}\text { I0-fold increased oral bioavailability in a } \mathrm{pH} \text {-sensitive } \\
\text { hydrogel and effective at inhibiting tumor growth in a } \\
\text { 4TI breast cancer model }\end{array}$ & 118 \\
\hline 30. & $\beta$-casein & In vivo and in vitro & Improved oral bioavailability and toxicity & 119 \\
\hline 31. & Co-block polymeric micelles & In vivo and in vitro & $\begin{array}{l}2.52 \text {-fold increase in oral bioavailability with sustained } \\
\text { drug release }\end{array}$ & 120 \\
\hline 32. & Steric acid-modified Bletilla striata & In vivo & $\begin{array}{l}\text { 2- to } 4 \text {-fold increased oral bioavailability as compared to } \\
\text { IV Docetaxel }\end{array}$ & 121 \\
\hline 33. & $\begin{array}{l}\text { Co-block mixed polymer biotin-modified } \\
\text { micelles in alginate microparticles }\end{array}$ & In vivo and in vitro & $\begin{array}{l}27.4-\text { fold increased oral bioavailability and an } 84 \% \\
\text { increased cytotoxicity as compared to Docetaxel }\end{array}$ & 122 \\
\hline 34. & Tween 20 and Tween 80 & In vitro & $\begin{array}{l}\text { Improved solubility up to } 1500 \text {-fold with higher } \\
\text { anticancer activity against a } C 26 \text { colon cancer cell line }\end{array}$ & 123 \\
\hline 35. & Methoxy poly(ethylene glycol)-poly(lactide) & In vitro and in vivo & $84.4 \%$ inhibition of an oral epidermoid tumor & 124 \\
\hline \multicolumn{5}{|c|}{ Proniosome } \\
\hline 36. & TPGS proniosomes & In vitro and in vivo & $\begin{array}{l}\text { 7.3-fold increased oral bioavailability and increased } \\
\text { anticancer activity in MCF-7 tumor-bearing mice model }\end{array}$ & 127 \\
\hline \multicolumn{5}{|c|}{ Solid dispersion } \\
\hline 37. & Poloxamer F68/P85 & In vitro and in vivo & 2.97-fold increased oral bioavailability & 124 \\
\hline
\end{tabular}

Abbreviations: AUC, area under the curve; IV, intravenous; NP, nanoparticle; PEG, polyethylene glycol; PLGA, poly(lactic-co-glycolic acid); SNEDDS, self-nanoemulsifying drug delivery systems; SPION, superparamagnetic iron oxide nanoparticles; TPGS, docetaxel-loaded D- $\alpha$-tocopheryl polyethylene glycol I000 succinate.

science, toxicology, bioinformatics, molecular biology and medicine are expected to play an important role in the next decade.

\section{Conclusion and future prospects}

Given the recent technological advancements and knowledge accumulated over the past decades, we believe that smart targeted drug delivery carriers can be designed for the oral delivery of hydrophobic anticancer drugs such as DTX. Major barriers faced by DTX could easily be addressed using a nanotechnology-based novel drug delivery system by improving dissolution, increasing mucosal permeation, blocking P-gp efflux pump or pre-systemic metabolism leading to improved pharmacokinetics and pharmacodynamics of DTX. It is pertinent from the available literature that the oral administration of DTX will surely improve a patient's quality of life in addition to decreasing the cost of therapy as well as reducing the overall burden of the health care system, especially in developing countries.

With the dawn of nanotechnology in chemotherapeutics, in particular, for oral delivery, a number of questions need to be addressed and justified. The most important factor is the estimation of the toxicity profile of these nano-based drug delivery systems, although dedicated efforts are being made by numerous researchers in this regard. The results achieved so far using different nano-based delivery systems seem to be very encouraging and promising to increase the oral bioavailability of DTX, along with increasing its pharmacokinetics and improving its toxicity properties manifold. Furthermore, sincere efforts are being made in understanding the cellular interactions of various formulations and the mechanisms of their efficacy and safety profile. Nevertheless, more stringent research attempts are needed for the translation of laboratory success into 
product development. This could be achieved by focusing more on the ways to improve drug loading, release kinetics and the use of cost-effective materials and methods. Most of the reported studies have characterized such properties in vitro; yet, extensive in vivo evaluation is needed for better insight of the outcomes. Most importantly, more attempts should be made to explore new targeting moieties that can decrease unwanted side effects, which is a major concern with chemotherapy so far. Also, a detailed toxicological evaluation of these nanocarriers is needed for supporting the efficacy and safety of the formulation to be developed as a safe dosage for commercialization.

\section{Acknowledgments}

The authors are extremely thankful to their institutions for providing the necessary facilities and funding for this study.

\section{Disclosure}

The authors report no conflicts of interest in this work.

\section{References}

1. Thanki K, Gangwal RP, Sangamwar AT, Jain S. Oral delivery of anticancer drugs: challenges and opportunities. J Control Release. 2013; 170(1):15-40.

2. Torre LA, Bray F, Siegel RL, Ferlay J, Lortet-Tieulent J, Jemal A. Global cancer statistics, 2012. CA Cancer J Clin. 2015;65(2):87-108.

3. Vineis P, Wild CP. Global cancer patterns: causes and prevention. Lancet. 2014;383(9916):549-557.

4. Fojo T, Lo AW. Price, value, and the cost of cancer drugs. Lancet Oncol. 2016;17(1):3-5.

5. Cojoc M, Peitzsch C, Trautmann F, Polishchuk L, Telegeev GD, Dubrovska A. Emerging targets in cancer management: role of the CXCL12/CXCR4 axis. Onco Targets Ther. 2013;6:1347-1361.

6. Albain KS, Swann RS, Rusch VW, et al. Radiotherapy plus chemotherapy with or without surgical resection for stage III non-small-cell lung cancer: a phase III randomised controlled trial. Lancet. 2009; 374(9687):379-386.

7. Liu G, Franssen E, Fitch MI, Warner E. Patient preferences for oral versus intravenous palliative chemotherapy. J Clin Oncol. 1997;15(1): $110-115$.

8. Le Lay K, Myon E, Hill S, et al. Comparative cost-minimisation of oral and intravenous chemotherapy for first-line treatment of non-small cell lung cancer in the UK NHS system. Eur J Health Econ. 2007; $8(2): 145-151$.

9. Bedell $\mathrm{CH}$. A changing paradigm for cancer treatment: the advent of new oral chemotherapy agents. Clin J Oncol Nurs. 2003;7(6):5-9.

10. Kato M, Chiba K, Hisaka A, et al. The intestinal first-pass metabolism of substrates of CYP3A4 and P-glycoprotei - quantitative analysis based on information from the literature. Drug Metab Pharmacokinet. 2003;18(6):365-372.

11. Budha N, Frymoyer A, Smelick G, et al. Drug absorption interactions between oral targeted anticancer agents and PPIs: is pH-dependent solubility the Achilles heel of targeted therapy? Clin Pharmacol Ther. 2012;92(2):203-213.

12. Chidambaram M, Manavalan R, Kathiresan K. Nanotherapeutics to overcome conventional cancer chemotherapy limitations. J Pharm Pharm Sci. 2011;14(1):67-77.
13. Aisner J. Overview of the changing paradigm in cancer treatment: oral chemotherapy. Am J Health Syst Pharm. 2007;64(9):S4-S7.

14. Yum SI, Schoenhard G, Tipton AJ, Gibson JW, Middleton JC. Oral Drug Delivery System. Google Patents; 2013.

15. Dharmadhikari NB, Zala YR, Singh A. Oral Drug Delivery System. Google Patents; 2013.

16. Jeanneret L, Schneider M, Troxler S, Bugnon O, Lüthi F. Adhésion thérapeutique aux traitements oncologiques oraux et prise en charge interdisciplinaire [Therapeutic adherence to oral cancer therapy and interdisciplinary management]. Rev Med Suisse. 2011;7(296):1154-1158, 1160. French.

17. Masaoka Y, Tanaka Y, Kataoka M, Sakuma S, Yamashita S. Site of drug absorption after oral administration: assessment of membrane permeability and luminal concentration of drugs in each segment of gastrointestinal tract. Eur J Pharm Sci. 2006;29(3):240-250.

18. Helander HF, Fändriks L. Surface area of the digestive tract-revisited. Scand J Gastroenterol. 2014;49(6):681-689.

19. Banna GL, Collovà E, Gebbia V, et al. Anticancer oral therapy: emerging related issues. Cancer Treat Rev. 2010;36(8):595-605.

20. Chaurasiya A, Singh AK, Jain GK, et al. Dual approach utilizing self microemulsifying technique and novel P-gp inhibitor for effective delivery of taxanes. J Microencapsul. 2012;29(6):583-595.

21. Jibodh RA, Lagas JS, Nuijen B, Beijnen JH, Schellens JH. Taxanes: old drugs, new oral formulations. Eur J Pharmacol. 2013;717(1): 40-46.

22. Moes J. Development and Clinical Application of Oral Dosage Forms of Taxanes. Amsterdam: 2013.

23. Do DP. Drug delivery systems for cancer therapeutics. US Pharm. 2011;36(9):12-15.

24. Wang S, Zhou Y, Zhuang B, et al. Star-shaped amphiphilic block polyurethane with pentaerythritol core for a hydrophobic drug delivery carrier. Polym Int. 2016.

25. The Cost Of Creating A New Drug Now \$5 Billion, Pushing Big Pharma To Change. Forbes; 2013. Accessed https:/www.forbes.com/sites/ matthewherper/2013/08/11/how-the-staggering-cost-of-inventing-newdrugs-is-shaping-the-future-of-medicine/\#417710fb13c3. Accessed December 1, 2017.

26. Hill RG. Drug Discovery and Development: Technology in Transition. Elsevier Health Sciences: London, UK;2012:30-38.

27. Mei L, Zhang Z, Zhao L, et al. Pharmaceutical nanotechnology for oral delivery of anticancer drugs. Adv Drug Deliv Rev. 2013;65(6): $880-890$.

28. Halfdanarson TR, Jatoi A. Oral cancer chemotherapy: the critical interplay between patient education and patient safety. Curr Oncol Rep. 2010;12(4):247-252.

29. O'neill V, Twelves C. Oral cancer treatment: developments in chemotherapy and beyond. Br J Cancer. 2002;87(9):933-937.

30. Uoto K, Mitsui I, Terasawa H, Soga T. First synthesis and cytotoxic activity of novel docetaxel analogs modified at the C18-position. Bioorg Med Chem Lett. 1997;7(23):2991-2996.

31. Cortes JE, Pazdur R. Docetaxel. J Clin Oncol. 1995;13(10):2643-2655.

32. Verweij J, Clavel M, Chevalier B. Paclitaxel (TaxolTM) and docetaxel (TaxotereTM): Not simply two of a kind. Ann Oncol. 1994;5(6): 495-505.

33. Lwin Z, Leighl N. Economic evaluation of docetaxel for breast cancer. Expert Opin Pharmacother. 2009;10(2):283-290.

34. Kaye S; Scottish Gynaecological Cancer Trials Group. The integration of docetaxel into first-line chemotherapy for ovarian cancer. Int J Gynecol Cancer. 2001;11(s1):31-33.

35. Belani CP, Eckardt J. Development of docetaxel inadvanced nonsmall-cell lung cancer. Lung Cancer. 2004;46:S3-S11.

36. Catimel G, Verweij J, Mattijssen V, et al. Docetaxel (Taxotere $^{\circledR}$ ): an active drug for the treatment of patients with advanced squamous cell carcinoma of the head and neck. Ann Oncol. 1994;5(6):533-537.

37. Roth A, Maibach R, Martinelli G, et al. Docetaxel (Taxotere $^{\sqrt{\mathbb{R}}}$ )-cisplatin (TC): an effective drug combination in gastric carcinoma. Ann Oncol.2000; 11(3):301-306. 
38. Picus J, Schultz M. Docetaxel (Taxotere) as monotherapy in the treatment of hormone-refractory prostate cancer: preliminary results. Paper presented at: Seminars in Oncology, 1999.

39. Engels F, Sparreboom A, Mathot R, Verweij J. Potential for improvement of docetaxel-based chemotherapy: a pharmacological review. Br J Cancer. 2005;93(2):173-177.

40. Baker J, Ajani J, Scotté F, et al. Docetaxel-related side effects and their management. Eur J Oncol Nurs. 2009;13(1):49-59.

41. Schellens JH, Malingré MM, Kruijtzer CMF, et al. Modulation of oral bioavailability of anticancer drugs: from mouse to man. Eur J Pharm Sci. 2000;12(2):103-110.

42. Stuurman FE, Nuijen B, Beijnen JH, Schellens JH. Oral anticancer drugs: mechanisms of low bioavailability and strategies for improvement. Clin Pharmacokinet. 2013;52(6):399-414.

43. Baker SD, Sparreboom A, Verweij J. Clinical pharmacokinetics of docetaxel. Clin Pharmacokinet. 2006;45(3):235-252.

44. Lipinski CA. Lead-and drug-like compounds: the rule-of-five revolution. Drug Discov Today Technol. 2004;1(4):337-341.

45. Fayad W, Rickardson L, Haglund C, et al. Identification of agents that induce apoptosis of multicellular tumour spheroids: enrichment for mitotic inhibitors with hydrophobic properties. Chem Biol Drug Des. 2011;78(4):547-557.

46. Stangier J. Clinical pharmacokinetics and pharmacodynamics of the oral direct thrombin inhibitor dabigatran etexilate. Clin Pharmacokinet 2008;47(5):285-295.

47. Siepmann J, Siepmann F. Modeling of diffusion controlled drug delivery. J Control Release. 2012;161(2):351-362.

48. Brouwers J, Brewster ME, Augustijns P. Supersaturating drug delivery systems: The answer to solubility-limited oral bioavailability? J Pharm Sci. 2009;98(8):2549-2572.

49. Moes J, Koolen S, Huitema A, Schellens J, Beijnen J, Nuijen B. Pharmaceutical development and preliminary clinical testing of an oral solid dispersion formulation of docetaxel (ModraDoc001). Int J Pharm. 2011;420(2):244-250.

50. Lim SM, Pang ZW, Tan HY, Shaikh M, Adinarayana G, Garg S. Enhancement of docetaxel solubility using binary and ternary solid dispersion systems. Drug Dev Ind Pharm. 2015;41(11):1847-1855.

51. Malingré MM, Beijnen JH, Schellens JH. Oral delivery of taxanes. Invest New Drugs. 2001;19(2):155-162.

52. Veber DF, Johnson SR, Cheng H-Y, Smith BR, Ward KW, Kopple KD. Molecular properties that influence the oral bioavailability of drug candidates. J Med Chem. 2002;45(12):2615-2623.

53. Engels FK, Ten Tije AJ, Baker SD, et al. Effect of cytochrome P450 3A4 inhibition on the pharmacokinetics of docetaxel. Clin Pharmacol Ther. 2004;75(5):448-454.

54. Urien S, Barré J, Morin C, Paccaly A, Montay G, Tillement J-P. Docetaxel serum protein binding with high affinity to alpha1-acid glycoprotein. Invest New Drugs. 1996;14(2):147-151.

55. Eckford PD, Sharom FJ. ABC efflux pump-based resistance to chemotherapy drugs. Chem Rev. 2009;109(7):2989-3011.

56. Varma MV, Ashokraj Y, Dey CS, Panchagnula R. P-glycoprotein inhibitors and their screening: a perspective from bioavailability enhancement. Pharmacol Res. 2003;48(4):347-359.

57. Shirakawa K, Takara K, Tanigawara Y, et al. Interaction of Docetaxel ("Taxotere") with Human P-Glycoprotein. Jpn J Cancer Res. 1999; 90(12):1380-1386.

58. Kunjachan S, Rychlik B, Storm G, Kiessling F, Lammers T. Multidrug resistance: Physiological principles and nanomedical solutions. $A d v$ Drug Deliv Rev. 2013;65(13):1852-1865.

59. Blagosklonny MV. Analysis of FDA approved anticancer drugs reveals the future of cancer therapy. Cell Cycle. 2004;3(8):1033-1040.

60. Baker SD, Zhao M, He P, Carducci MA, Verweij J, Sparreboom A. Simultaneous analysis of docetaxel and the formulation vehicle polysorbate 80 in human plasma by liquid chromatography/tandem mass spectrometry. Anal Biochem. 2004;324(2):276-284.

61. Mazzaferro S, Bouchemal K, Ponchel G. Oral delivery of anticancer drugs I: general considerations. Drug Discov Today. 2013;18(1): $25-34$.
62. Engels FK, Mathot RA, Verweij J. Alternative drug formulations of docetaxel: a review. Anticancer Drugs. 2007;18(2):95-103.

63. Panday VRN, Huizing MT, Huinink WWTB, Vermorken JB, Beijnen JH. Hypersensitivity reactions to the taxanes paclitaxel and docetaxel. Clin Drug Investig. 1997;14(5):418-427.

64. Extra J-M, Rousseau F, Bruno R, Clavel M, Le Bail N, Marty M. Phase I and pharmacokinetic study of Taxotere (RP 56976; NSC 628503) given as a short intravenous infusion. Cancer Res. 1993;53(5):1037-1042.

65. Mark M, Walter R, Meredith DO, Reinhart WH. Commercial taxane formulations induce stomatocytosis and increase blood viscosity. Br J Pharmacol. 2001;134(6):1207-1214.

66. McEntee M, Silverman J, Rassnick K, et al. Enhanced bioavailability of oral docetaxel by co-administration of cyclosporin A in dogs and rats. Vet Comp Oncol. 2003;1(2):105-112.

67. Malingré MM, Richel DJ, Beijnen JH, et al. Coadministration of cyclosporine strongly enhances the oral bioavailability of docetaxel. J Clin Oncol. 2001;19(4):1160-1166.

68. Patel K, Chowdhury N, Doddapaneni R, Boakye CH, Godugu C, Singh M. Piperlongumine for enhancing oral bioavailability and cytotoxicity of Docetaxel in triple-negative breast cancer. J Pharm Sci. 2015; 104(12):4417-4426.

69. van Waterschoot RA, Lagas JS, Wagenaar E, et al. Absence of both cytochrome P450 3A and P-glycoprotein dramatically increases docetaxel oral bioavailability and risk of intestinal toxicity. Cancer Res. 2009;69(23):8996-9002.

70. Bu X, Zhu T, Ma Y, Shen Q. Co-administration with cell penetrating peptide enhances the oral bioavailability of docetaxel-loaded nanoparticles. Drug Dev Ind Pharm. 2015;41(5):764-771.

71. Farokhzad OC, Langer R. Impact of nanotechnology on drug delivery. ACS Nano. 2009;3(1):16-20.

72. Kompella UB. Nanotechnology and drug delivery. J Ocul Pharmacol Ther. 2013;29(2):89-89.

73. Park K. Facing the truth about nanotechnology in drug delivery. ACS Nano. 2013;7(9):7442-7447.

74. Sun T, Zhang YS, Pang B, Hyun DC, Yang M, Xia Y. Engineered nanoparticles for drug delivery in cancer therapy. Angew Chem Int Ed Engl. 2014;53(46):12320-12364.

75. Sinha R, Kim GJ, Nie S, Shin DM. Nanotechnology in cancer therapeutics: bioconjugated nanoparticles for drug delivery. Mol Cancer Ther. 2006;5(8):1909-1917.

76. Jiang W, Kim BY, Rutka JT, Chan WC. Advances and challenges of nanotechnology-based drug delivery systems. Expert Opin Drug Deliv. 2007;4(6):621-633.

77. Parveen S, Misra R, Sahoo SK. Nanoparticles: a boon to drug delivery, therapeutics, diagnostics and imaging. Nanomedicine. 2012;8(2): $147-166$.

78. Walko CM, McLeod HL. Personalizing medicine in geriatric oncology. J Clin Oncol. 2014;32(24):2581-2586.

79. Win KY, Feng S-S. Effects of particle size and surface coating on cellular uptake of polymeric nanoparticles for oral delivery of anticancer drugs. Biomaterials. 2005;26(15):2713-2722.

80. Volkheimer G. Persorption of particles: physiology and pharmacology. Adv Pharmacol Chemother. 1977;14:163-187.

81. Mei L, Zhang Y, Zheng Y, et al. A novel docetaxel-loaded poly ( $\varepsilon$-caprolactone)/pluronic F68 nanoparticle overcoming multidrug resistance for breast cancer treatment. Nanoscale Res Lett. 2009;4(12): 1530 .

82. Feng S-S, Mei L, Anitha P, Gan CW, Zhou W. Poly (lactide)-vitamin E derivative/montmorillonite nanoparticle formulations for the oral delivery of Docetaxel. Biomaterials. 2009;30(19):3297-3306.

83. Saremi S, Dinarvand R, Kebriaeezadeh A, Ostad SN, Atyabi F. Enhanced oral delivery of docetaxel using thiolated chitosan nanoparticles: preparation, in vitro and in vivo studies. Biomed Res Int. 2013; 2013.

84. Hu K, Cao S, Hu F, Feng J. Enhanced oral bioavailability of docetaxel by lecithin nanoparticles: preparation, in vitro, and in vivo evaluation. Int J Nanomedicine. 2012;7:3537-3545. 
85. Mazzaferro S, Bouchemal K, Skanji R, Gueutin C, Chacun H, Ponchel G. Intestinal permeation enhancement of docetaxel encapsulated into methyl- $\beta$-cyclodextrin/poly (isobutylcyanoacrylate) nanoparticles coated with thiolated chitosan. J Control Release. 2012;162(3):568-574.

86. Mazzaferro S, Bouchemal K, Maksimenko A, Skanji R, Opolon P, Ponchel G. Reduced intestinal toxicity of docetaxel loaded into mucoadhesive nanoparticles, in mouse xenograft model. J Colloid Sci Biotechnol. 2012;1(2):210-217.

87. Wu J, Bu X, Dou L, Fang L, Shen Q. Co-delivery of Docetaxel and Berbamine by Chitosan/Sulfobutylether- $\beta$-Cyclodextrin nanoparticles for enhancing bioavailability and anticancer activities. J Biomed Nanotechnol. 2015;11(10):1847-1857.

88. Ahmad N, Alam MA, Ahmad R, Naqvi AA, Ahmad FJ. Preparation and characterization of surface-modified PLGA-polymeric nanoparticles used to target treatment of intestinal cancer. Artif Cells Nanomed Biotechnol. 2018;46(2):432-446.

89. Saremi S, Atyabi F, Akhlaghi SP, Ostad SN, Dinarvand R. Thiolated chitosan nanoparticles for enhancing oral absorption of docetaxel: preparation, in vitro and ex vivo evaluation. Int $J$ Nanomedicine. 2011;6:119.

90. Chime SA, Onyishi IV. Lipid-based drug delivery systems (LDDS): Recent advances and applications of lipids in drug delivery. Afr $J$ Pharm Pharmacol. 2013;7(48):3034-3059.

91. Meyerhoff A. US Food and Drug Administration approval of AmBisome (liposomal amphotericin B) for treatment of visceral leishmaniasis. Clin Infect Dis. 1999;28(1):42-48.

92. Pillai G. Nanomedicines for cancer therapy: an update of FDA approved and those under various stages of development. SOJ Pharm Pharm Sci. 2014;1(2):13.

93. Pattni BS, Chupin VV, Torchilin VP. New developments in liposomal drug delivery. Chem Rev. 2015;115(19):10938-10966.

94. Gregoriadis G. Engineering liposomes for drug delivery: progress and problems. Trends Biotechnol. 1995;13(12):527-537.

95. Sun B, Luo C, Li L, et al. Core-matched encapsulation of an oleate prodrug into nanostructured lipid carriers with high drug loading capability to facilitate the oral delivery of docetaxel. Colloids Surf B Biointerfaces. 2016;143:47-55.

96. Fang G, Tang B, Chao Y, et al. Cysteine-functionalized nanostructured lipid carriers for oral delivery of docetaxel: a permeability and pharmacokinetic study. Mol Pharm. 2015;12(7):2384-2395.

97. Cho H-J, Park JW, Yoon I-S, Kim D-D. Surface-modified solid lipid nanoparticles for oral delivery of docetaxel: enhanced intestinal absorption and lymphatic uptake. Int J Nanomedicine. 2014;9:495.

98. Madni A, Tahir N, Rehman M, et al. Hybrid Nano-carriers for potential drug delivery. In: Advanced Technology for Delivering Therapeutics. Rijeka, Croatia: InTech; 2017.

99. Liu Y, Li K, Pan J, Liu B, Feng S-S. Folic acid conjugated nanoparticles of mixed lipid monolayer shell and biodegradable polymer core for targeted delivery of Docetaxel. Biomaterials. 2010;31(2):330-338.

100. Sohail MF, Javed I, Hussain SZ, et al. Folate grafted thiolated chitosan enveloped nanoliposomes with enhanced oral bioavailability and anticancer activity of docetaxel. J Mater Chem B. 2016;4(37): 6240-6248.

101. Zhang Y, Zhu W, Zhang H, et al. Carboxymethyl chitosan/phospholipid bilayer-capped mesoporous carbon nanoparticles with $\mathrm{pH}$-responsive and prolonged release properties for oral delivery of the antitumor drug, Docetaxel. Int J Pharm. 2017;532(1):384-392.

102. Attili-Qadri S, Karra N, Nemirovski A, et al. Oral delivery system prolongs blood circulation of docetaxel nanocapsules via lymphatic absorption. Proc Natl Acad Sci US A. 2013;110(43):17498-17503.

103. Muthu MS, Kulkarni SA, Raju A, Feng S-S. Theranostic liposomes of TPGS coating for targeted co-delivery of docetaxel and quantum dots. Biomaterials. 2012;33(12):3494-3501.

104. Shanavas A, Sasidharan S, Bahadur D, Srivastava R. Magnetic coreshell hybrid nanoparticles for receptor targeted anti-cancer therapy and magnetic resonance imaging. J Colloid Interface Sci. 2017;486: $112-120$.
105. Yin Y-M, Cui F-D, Mu C-F, et al. Docetaxel microemulsion for enhanced oral bioavailability: preparation and in vitro and in vivo evaluation. J Control Release. 2009;140(2):86-94.

106. Verma P, Meher JG, Asthana S, Pawar VK, Chaurasia M, Chourasia MK. Perspectives of nanoemulsion assisted oral delivery of docetaxel for improved chemotherapy of cancer. Drug Deliv. 2016;23(2): 479-488.

107. Pandey G, Mittapelly N, Valicherla GR, et al. P-gp modulatory acetyl-11-keto- $\beta$-boswellic acid based nanoemulsified carrier system for augmented oral chemotherapy of docetaxel. Colloids Surf B Biointerfaces. 2017;155:276-286.

108. Seo YG, Kim DH, Ramasamy T, et al. Development of docetaxelloaded solid self-nanoemulsifying drug delivery system (SNEDDS) for enhanced chemotherapeutic effect. Int J Pharm. 2013;452(1): $412-420$.

109. Quan Q, Kim D-W, Marasini N, et al. Physicochemical characterization and in vivo evaluation of solid self-nanoemulsifying drug delivery system for oral administration of docetaxel. J Microencapsul. 2013; 30(4):307-314.

110. Chen Y, Chen C, Zheng J, Chen Z, Shi Q, Liu H. Development of a solid supersaturatable self-emulsifying drug delivery system of docetaxel with improved dissolution and bioavailability. Biol Pharm Bull. 2011;34(2):278-286.

111. Yan Y-D, Marasini N, Choi YK, et al. Effect of dose and dosage interval on the oral bioavailability of docetaxel in combination with a curcumin self-emulsifying drug delivery system (SEDDS). Eur $J$ Drug Metab Pharmacokinet. 2012;37(3):217-224.

112. Valicherla GR, Dave KM, Syed AA, et al. Formulation optimization of Docetaxel loaded self-emulsifying drug delivery system to enhance bioavailability and anti-tumor activity. Sci Rep. 2016;6:26895.

113. Lee E, Kim H, Lee I-H, Jon S. In vivo antitumor effects of chitosanconjugated docetaxel after oral administration. J Control Release. 2009;140(2):79-85.

114. Khatun Z, Nurunnabi M, Reeck GR, Cho KJ, Lee Y-K. Oral delivery of taurocholic acid linked heparin-docetaxel conjugates for cancer therapy. J Control Release. 2013;170(1):74-82.

115. Liu F, Feng L, Zhang L, Zhang X, Zhang N. Synthesis, characterization and antitumor evaluation of CMCS-DTX conjugates as novel delivery platform for docetaxel. Int J Pharm. 2013;451(1):41-49.

116. Gaucher G, Satturwar P, Jones M-C, Furtos A, Leroux J-C. Polymeric micelles for oral drug delivery. Eur J Pharm Biopharm. 2010;76(2): $147-158$.

117. Jones M-C, Leroux J-C. Polymeric micelles-a new generation of colloidal drug carriers. Eur J Pharm Biopharm. 1999;48(2):101-111.

118. Wang Y, Chen L, Tan L, et al. PEG-PCL based micelle hydrogels as oral docetaxel delivery systems for breast cancer therapy. Biomaterials. 2014;35(25):6972-6985.

119. Shapira A, Assaraf YG, Epstein D, Livney YD. Beta-casein nanoparticles as an oral delivery system for chemotherapeutic drugs: impact of drug structure and properties on co-assembly. Pharm Res. 2010; 27(10):2175-2186.

120. Dou J, Zhang H, Liu X, Zhang M, Zhai G. Preparation and evaluation in vitro and in vivo of docetaxel loaded mixed micelles for oral administration. Colloids Surf B Biointerfaces. 2014;114:20-27.

121. Guan Q, Sun D, Zhang G, et al. Docetaxel-loaded self-assembly stearic acid-modified bletilla striata polysaccharide micelles and their anticancer effect: preparation, characterization, cellular uptake and in vitro evaluation. Molecules. 2016;21(12):1641.

122. Shen Y, Hu M, Qiu L. Sequentially dual-targeting vector with nanoin-micro structure for improved docetaxel oral delivery in vivo. Nanomedicine. 2016;11(23):3071-3086.

123. Hekmat A, Attar H, Seyf Kordi AA, Iman M, Jaafari MR. New oral formulation and in vitro evaluation of Docetaxel-loaded nanomicelles. Molecules. 2016;21(9):1265.

124. Song CK, Yoon I-S, Kim D-D. Poloxamer-based solid dispersions for oral delivery of docetaxel: Differential effects of F68 and P85 on oral docetaxel bioavailability. Int J Pharm. 2016;507(1):102-108. 
125. Radha G, Rani TS, Sarvani B. A review on proniosomal drug delivery system for targeted drug action. J Basic Clin Pharm. 2013;4(2):42.

126. Liu H, Hu K, Feng J. [Development and characterization of TPGS modified proniosomes of docetaxel]. Zhongguo Zhong yao za zhi= Zhongguo zhongyao zazhi= China journal of Chinese materia medica 2015;40(19):3775-3779. Chinese.

127. Liu H, Tu L, Zhou Y, et al. Improved bioavailability and antitumor effect of Docetaxel by TPGS modified proniosomes: in vitro and in vivo evaluations. Sci Rep. 2017;7:1-11.

128. De Jong WH, Borm PJ. Drug delivery and nanoparticles: applications and hazards. Int J Nanomedicine. 2008;3(2):133.

129. Grabowski N, Hillaireau H, Vergnaud J, et al. Surface coating mediates the toxicity of polymeric nanoparticles towards human-like macrophages. Int J Pharm. 2015;482(1):75-83.

130. Garcia SC, Guterres SS, Bubols GB, Bulcao RP, Charao MF, Pohlmann AR. Polymeric nanoparticles: toxicological evaluation, cardiotoxicity, and hepatotoxicity. In: Duran N, Guterres SS, Alves OI, editors. Nanotoxicology: Materials, Methodologies, and Assessments. New York: Springer Science Business Media; 2014:299-324.
131. Giardiello M, Liptrott NJ, McDonald TO, et al. Accelerated oral nanomedicine discovery from miniaturized screening to clinical production exemplified by paediatric HIV nanotherapies. Nat Commun. 2016;7(13184):1-10.

132. Johnson JR, Ning Y-M, Farrell A, Justice R, Keegan P, Pazdur R. Accelerated approval of oncology products: the food and drug administration experience. J Natl Cancer Inst. 2011;103(8):636-644.

133. Rehman M, Madni A, Webster TJ. The era of biofunctional biomaterials in orthopedics: what does the future hold? Expert Rev Med Devices. 2018;15(3):193-204.

134. Wu J, Shen Q, Fang L. Sulfobutylether- $\beta$-cyclodextrin/chitosan nanoparticles enhance the oral permeability and bioavailability of docetaxel. Drug Dev Ind Pharm. 2013;39(7):1010-1019.
International Journal of Nanomedicine

\section{Publish your work in this journal}

The International Journal of Nanomedicine is an international, peerreviewed journal focusing on the application of nanotechnology in diagnostics, therapeutics, and drug delivery systems throughout the biomedical field. This journal is indexed on PubMed Central, MedLine, CAS, SciSearch ${ }^{\circledR}$, Current Contents ${ }^{\circledR} /$ Clinical Medicine,

\section{Dovepress}

Journal Citation Reports/Science Edition, EMBase, Scopus and the Elsevier Bibliographic databases. The manuscript management system is completely online and includes a very quick and fair peer-review system, which is all easy to use. Visit http://www.dovepress.com/ testimonials.php to read real quotes from published authors.

Submit your manuscript here: http://www.dovepress.com/international-journal-of-nanomedicine-journal 